\title{
Reforestation of 'Village Forest' to Improve Sustaiability Creative Industries in Desa Siponjot
}

\author{
Noverita Sprinse Vinolina ${ }^{1 *}$, Antonio Marro Sipayung ${ }^{1}$, Dardanila $^{2}$, Sondang Pintauli ${ }^{3}$ \\ ${ }^{1}$ Faculty of Agriculture, Universitas Sumatera Utara \\ ${ }^{2}$ Faculty of Cultural Study, Universitas Sumatera Utara \\ ${ }^{3}$ Faculty of Dentistry, Universitas Sumatera Utara \\ *Email: noverita@usu.ac.id
}

\begin{abstract}
This program is conducted to assist Siponjot Village while empowering the people of Siponjot Village to be able to utilize and maximize the benefit of the village forest. Village forest might support the availability of raw materials required for making musical instruments, such as high quality of wood, including how to process wood waste from making musical instruments to be used as creative souvenirs and improve the economic value. The raw material for production determined its results of the production of wood-based musical instruments. Thus, in order to produce a high quality tanginang, hasapi, and gondang, which previously began to be produced by arts crafts in the Sitangkubang area of Siponjot Village, a high quality of raw materials is needed. The community service team surveyed the location of planting seeds for village forest restoration, provided socialization related to the importance of village forest cultivation and the suitability of the Siponjot Village area for the cultivation of these plants. Village forest restoration aims to maintain the beauty and beauty of the village. Implementation of village reforestation activities starting from socializing forest tourism and the strength of village forests to the community, followed by a discussion about village forest management and its economic benefits. Handover of a thousand units of forest plant seedlings given to the villagers of Siponjot as part of the forest restoration program in the area.
\end{abstract}

\section{Keywords: Village Forest, Empowering Foresty, Replanting and Reforestation, Community Services}

\begin{abstract}
Abstrak
Pengabdian program desa binaan di Desa Siponjot bertujuan memberdayakan masyarakat Desa Siponjot agar mampu merawat, memanfaatkan dan mengolah hutan desa, sehingga hutan desa dapat mendukung ketersediaan materi dasar pembuatan instrumen musik, yaitu kayu, termasuk bagaimana mengolah limbah kayu sisa pembuatan instrumen musikal untuk dijadikan souvenir kreatif dan bernilai ekonomis. Bahan baku produksi sangat menentukan hasil dari produksi alat musik berbahan dasar kayu, seperti tanginang, hasapi, juga gondang yang sebelumnya mulai diproduksi huta seni di wilayah Sitangkubang Desa Siponjot. Tim pengabdian melakukan survei lokasi penanaman bibit untuk restorasi hutan desa, memberikan sosialisasi terkait pentingnya budidaya hutan desa serta kesesuaian wilayah Desa Siponjot untuk budidaya tanaman tersebut. Restorasi hutan desa bertujuan untuk menjaga keasrian dan keindahan desa. Pelaksanaan kegiatan restorasi hutan desa mulai dari sosialisasi wisata hutan serta kekuatan hutan desa kepada masyarakat, dilanjutkan dengan diskusi seputar pengelolaan hutan desa dan manfaatnya secara ekonomi. Penyerahan seribu unit bibit tanaman hutan yang diberikan kepada masyarakat Desa Siponjot sebagai bagian dari program restorasi hutan di wilayah tersebut.
\end{abstract}

Kata kunci: Hutan Desa, Pemberdayaan Hutan, Penanaman Kembali, Pengabdian kepada masyarakat 


\section{PENDAHULUAN}

\subsection{Latar Belakang Kegiatan}

Hutan Desa pada prinsipnya adalah Hutan Negara yang dikelola oleh masyarakat dalam organisasi administratif pedesaan yang dimanfaatkan untuk kesejahteraan masyarakat desa itu sendiri (Bambang Supriyanto, 2018). Artinya, Hutan Desa itu bermaksud untuk memberikan akses kepada masyarakat setempat melalui lembaga desa dalam memanfaatkan sumberdaya hutan secara lestari dengan harapan sebagai tujuannya adalah meningkatkan kesejahteraan masyarakat setempat secara berkelanjutan.

Pada dasarnya, penyelenggaraan hutan desa bertujuan untuk meningkatkan kesejahteraan masyarakat setempat secara berkelanjutan dan menjamin kelestarian lingkungan. Karena itu pelaku utama hutan desa adalah Lembaga Desa yang dalam hal ini lembaga kemasyarakatan yang ditetapkan dengan Peraturan Desa (Perdes) secara fungsional berada dalam organisasi desa dan bertanggung jawab kepada Kepala Desa dan diarahkan menjadi Badan Usaha Milik Desa (BUMDes). Dalam pelaksanaannya, program hutan desa pun diarahkan sesuai prinsip-prinsipnya bahwa 1) tidak mengubah status dan fungsi kawasan hutan; dan 2) ada keterkaitan masyarakat terhadap sumber daya hutan. Karena hutan mempunyai fungsi sosial, ekonomi, budaya dan ekologis (Budiono, Nugroho, Hardjanto, \& Nurrochmat, 2018). Jadi pengelolaan hutan desa berorientasi ekonomi perlu juga mempertimbangkan aspek lainnya yang merupakan satu-kesatuan tak terpisahkan. Jika prinsip ini tidak dipahami baik, maka yang akan terjadi adalah kerusakan hutan yang membawa akibat buruk pada seluruh aspek kehidupan manusia dan lingkungannya. Satu hal yang penting untuk diperhatikan adalah hutan desa merupakan hutan negara yang dikelola oleh masyarakat lembaga desa, sehingga untuk menerapkan pengelolaan hutan desa harus berlandaskan aturan hukum negara dan atau kebijakan pemerintah baik pusat maupun daerah. Oleh karena itu hutan desa memiliki beberapa kriteria, diantaranya: 1) kawasan hutan desa berada dalam kawasan hutan negara seperti hutan lindung dan hutan produksi; 2) belum dibebani hak pengelolaan atau izin pemanfaatan untuk bentuk pengelolaan lain; dan 3) kawasan hutan berada dalam wilayah administrasi desa yang bersangkutan.

Desa Siponjot saat ini belum memiliki hutan desa yang dapat digunakan untuk kepentingan bersama. Beberapa manfaat dari hutan desa ini antara lain pasokan bahan baku kayu yang berkualitas untuk mendukung Desa Siponjot sebagai desa seni (Maqbool, Rafiq, Imran, Quadeer, \& Abbas, 2014). Selain itu, kehadiran hutan desa juga dapat menjadi salah satu point of interest dari kunjungan wisata di masa yang akan datang. Oleh karena itu, penting bagi masyarakat desa untuk membentuk dan melestarikan hutan desa untuk keunggulan bersaing serta kompetitif di masa yang akan datang.

\subsection{Tujuan dan Manfaat Pelaksanaan}

Restorasi hutan desa menjadi salah satu bagian penting dalam pembentukan desa Siponjot sebagai desa seni. Hutan desa dapat menjadi bagian dari konteks wisata sekaligus menjadi bahan baku penting untuk pembuatan instrumen musik dan kerajinan berbasis kayu (Santika et al., 2017). Saat ini, banyak pohon mulai ditebangi sebagai kebutuhan bahan baku untuk produksi alat musik tanpa adanya restorasi hutan (Purba \& Lumbanraja, 2019). Jika kondisi ini dibiarkan, hutan lama kelamaan akan habis dan kualitas bahan baku yang dimiliki desa untuk pembuatan alat musik menjadi langka. Kegiatan pengabdian ini membiasakan masyarakat desa dalam program restorasi hutan serta pembibitan kembali untuk setiap pohon yang ditebang untuk keperluan ekonomi masyarakat desa. Program restorasi hutan sangat penting dalam menjaga keseimbangan alam, keseimbangan estetika desa, serta keunggulan bersaing untuk jangka panjang dari aktivitas produksi masyarakat desa (Fisher et al., 2018; Moeliono, Thuy, Bong, Wong, \& Brockhaus, 2017). Selain itu pembentukan hutan desa ditargetkan menjadi upaya dalam melindungi eksistensi hutan desa masyarakat Desa Siponjot, Humbang Hasundutan. Manfaat lain dari hutan desa ini akan mendukung Desa Siponjot sebagai desa seni, bukan hanya sekedar desa seni, namun menjadi desa seni yang tetap menjaga kelestarian lingkungan. Pepohonan merupakan bahan baku utama dari instrumen musik tradisional serta kerajinan berbahan dasar kayu. Restorasi hutan dan pembentukan hutan desa akan sangat membantu kelestarian hutan di masa yang akan datang. 


\subsection{Solusi yang Ditawarkan}

Kegiatan ini akan secara langsung dipraktekkan lewat berbagai contoh-contoh yang sudah dipersiapkan, dibantu oleh narasumber yang sudah pernah pernah melakukannya. Dalam konteks merawat hutan desa, misalnya, masyarakat akan diajarkan dan dilibatkan menata penanaman pohon yang baru di lahan-lahan yang selama ini tidak produktif, sehingga kelak hutan desa di samping menopang kebutuhan dasar materi pembuatan alat musik ke depannyajuga berfungsi menyehatkan dan memperindah wajah desa. Pada bagian ini masyarakat akan diberikan juga pemahaman tentang penggunaan bahan atau jenis kayu yang dapat digunakan sebagai alternatif pembuatan instrument. Target kegiatan ini adalah terlaksananya penanaman pohon-pohon baru di lahan-lahan yang tidak produktif di sekitar desa, dan tersedianya berbagai souvenir bernilai ekonomi yang dibuat berbahan dasar kayu, sisa pembuatan instrumen musik. Target berikutnya adalah bahwa dua atau tiga bulan pasca pembinaan desa ini, maka diharapkan akan tampak hutan desa yang subur, tersedianya sejumlah souvenir yang terbuat dari berbagai kayu dan siap untuk kemudian dipamerkan sesuai jadwal yang ada.

\section{METODE PELAKSANAAN}

Para pengrajin dan masyarakat desa (secara umum) belum sepenuhnya memahami tentang bagaimana mengelola hutan desa agar tetap bisa digunakan sebagai sumber bahan dasar pembuatan instrument musikal dan kerajinan tangan lainnya. Dengan demikian, tim mengadakan tatap muka serta diskusi secara dialogis untuk menyampaikan konsep-konsep pengelolaan hutan desa, termasuk bagaimana meremajakan hutan desa yang tidak produktif, bagaimana memanfaatkan pohon-pohon yang sudah tumbang dan terbengkalai. Pada sesi ini akan dilakukan peninjauan langsung ke area di mana pohon-pohon kayu tumbuh dan langsung mendiskusikan di lokasi tentang jenis-jenis kayu yang bisa dimanfaatkan sebagai alternatif untuk membuat instrument musikal. Dalam kegiatan ini akan juga dilakukan penanaman jenis-jenis pohon yang masa tanam dan tumbuh tidak terlalu lama. Artinya penggunaan kayu tersebut sebagai bahan dasar alternatif dapat digunakan dalam waktu yang tidak terlalu lama sesudah masa tanam. Para pengrajin termasuk masyarakat desa Siponjot secara umum belum memahami bagaimana cara menata desa agar sebuah desa mampu menunjukkan karakter atau aura huta seni (desa seni) yang kreatif, sehat dan berbudaya. Selain itu kegiatan ini juga mengadakan tatap muka serta diskusi secara dialogis, di mana akan disampaikan konsep-konsep tentang apa yang dimaksud dengan desa seni, desa seni yang kreatif, desa seni yang bersih, sehat dan berbudaya. Pada sesi ini akan dilakukan simulasi yang berkaitan dengan contohcontoh perilaku yang menjaga kebersihan desa, perilaku yang peduli lingkungan, serta perilaku yang sadar akan potensi desa sebagai penunjang ekonomi kreatif. Pada kegiatan ini akan dilakukan pembenahan terkait peralatan-peralatan umum untuk menjaga kebersihan desa dan memperindah wajah desa.

\section{HASIL DAN PEMBAHASAN}

Rangkaian pelaksanaan program restorasi hutan desa dilaksanakan dalam beberapa tahapan, mulai dari sosialisasi wisata hutan serta kekuatan hutan desa kepada masyarakat, dilanjutkan dengan diskusi seputar pengelolaan hutan desa dan manfaatnya secara ekonomi. Tim pengabdian melakukan survei lokasi penanaman bibit untuk resotrasi hutan desa, terkait kesesuaian tanah dan jenis tanaman yang akan dibudidayakan sebagai hutan desa. 


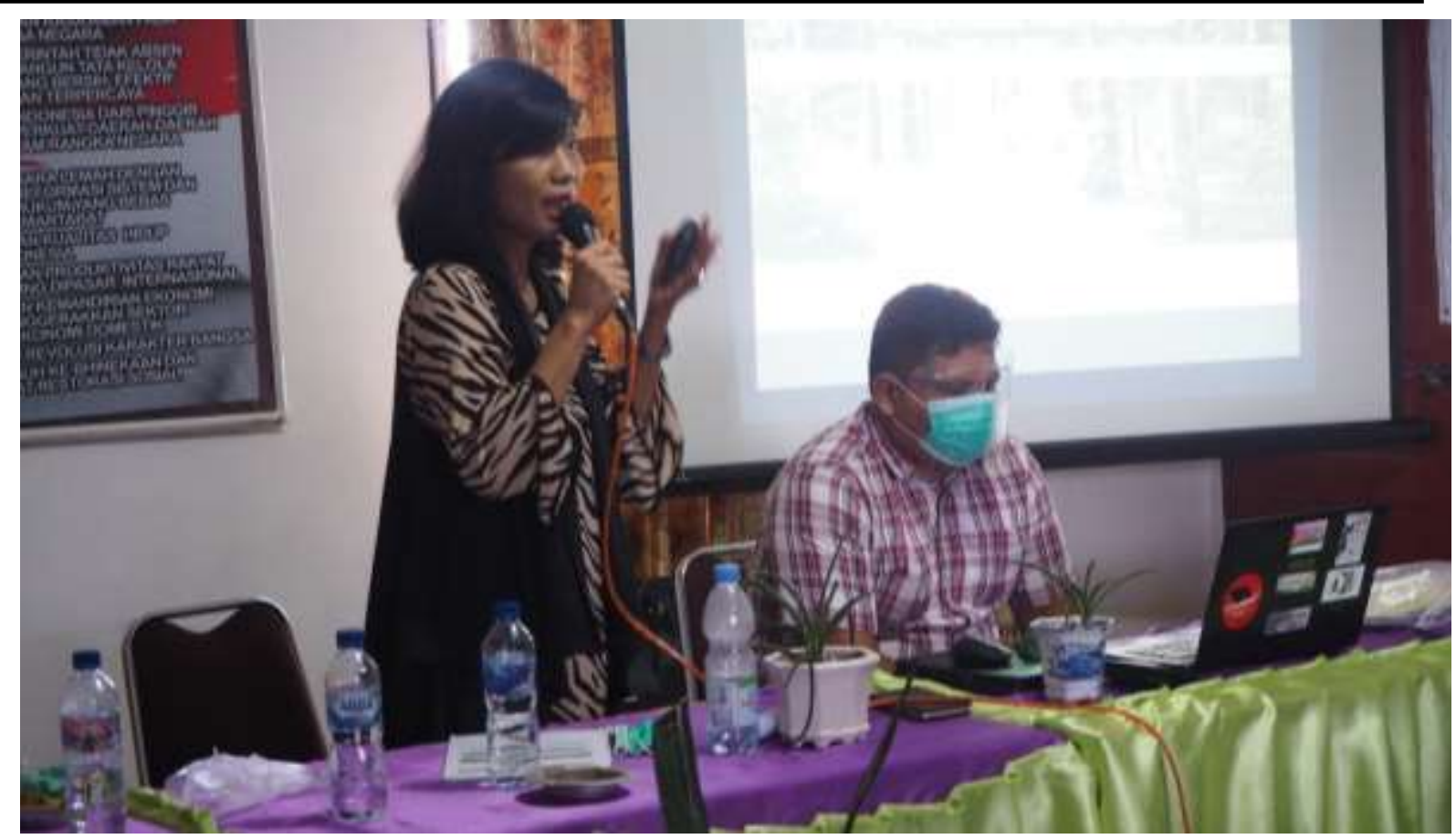

Gambar 3.1. Pemberian Sosialisasi Restorasi Hutan Desa

Pada kesempatan ini, Prof. Dr. Noverita Sprinse Vinolina, M.P, koordinator program restorasi hutan sekaligus guru besar Fakultas Pertanian USU memberikan sosialisasi terkait pentingnya budidaya hutan desa serta kesesuaian wilayah Desa Siponjot untuk budidaya tanaman tersebut. Restorasi hutan desa dimaksudkan untuk menjaga keasrian dan keindahan desa, bahkan dari beberapa lokasi penataan hutan yang bagus dapat menjadi objek wisata yang sangat diminati pengunjung. Restorasi hutan, selain menjaga keseimbangan dan kebersihan lingkungan, misalnya polusi udara, juga dapat dikembangkan menjadi sumber bahan baku produksi yang dapat digunakan masyarakat selaku pengerajin alat seni tradisional. Bahan baku produksi sangat menentukan hasil dari produksi alat musik berbahan dasar kayu, seperti tanginang, hasapi, juga gondang yang sebelumnya mulai diproduksi huta seni di wilayah Sitangkubang Desa Siponjot. Dengan demikian, restorasi hutan desa akan memberikan berbagai manfaat kepada masyarakat, mulai dari keindahan dan kebersihan lingkungan, akses ke sumber bahan baku berkualitas, serta potensi wisata dan potensi hasil ekonomi kepada masyarakat sekitar.

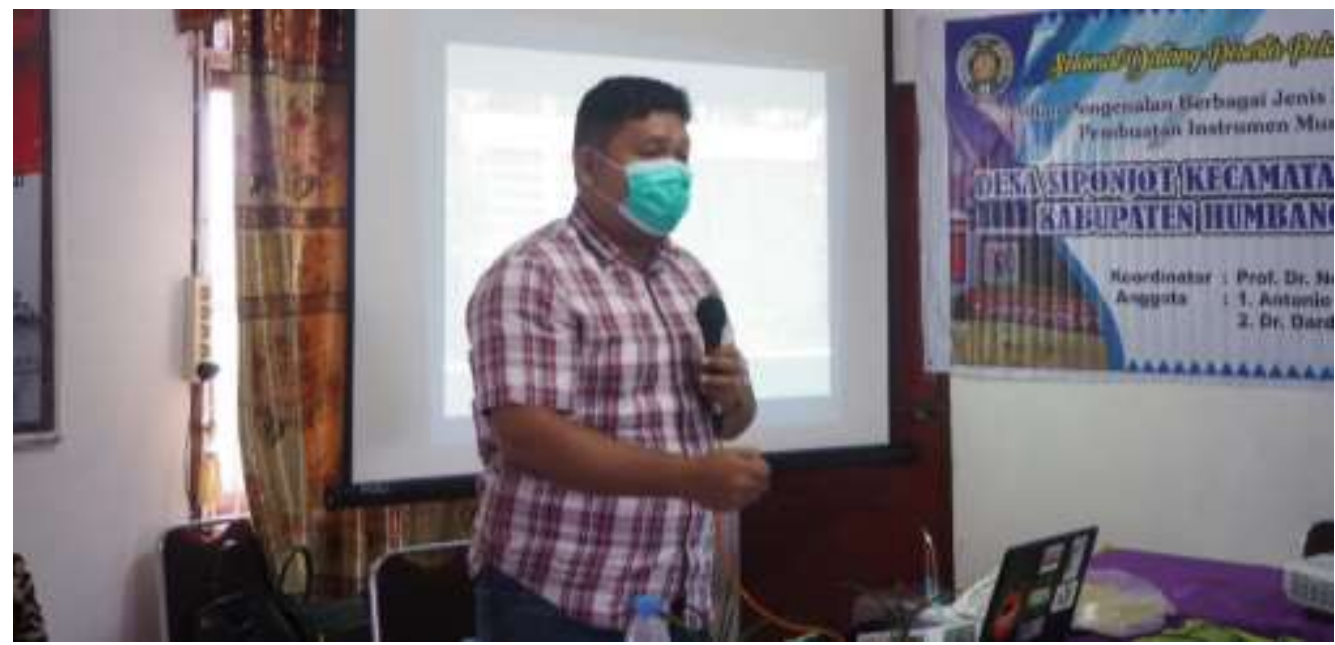

Gambar 3.2. Edukasi Pembentukan Hutan Desa 
Peraturan Menteri Kehutanan Republik Indonesia Nomor : P.89/Menhut-li/2014 Tentang Hutan Desa menjelaskan bahwa Hutan Desa adalah hutan negara yang belum dibebani izin/hak, yang dikelola oleh desa dan dimanfaatkan untuk kesejahteraan desa. Pembentukan hutan desa di Desa Siponjot pada awalnya dimaksudkan untuk melindungi legalitas hutan yang dimiliki Desa Siponjot. Pada beberapa situasi, hutan yang dimiliki desa umumnya tidak memiliki legalitas kepemilikan sehingga memicu perselisihan dari pihak lain ketika terjadi claim kepemilikan hutan dari pihak lain. Dari sisi hukum, hutan desa tanpa ada perlindungan hukum ataupun sertifikat kepemilikan akan menjadi lemah. Pada kondisi banding, masyarakat desa akan kehilangan kepemilikan hutan desa tersebut kepada pihak lain yang telah memiliki surat resmi kepemilikan desa. Pada kesempatan tersebut, tim pengabdian telah mengevaluasi bahwa saat ini belum ada hutan desa milik negara di wilayah Desa Siponjot. Oleh karena itu, tim pengabdian mengajukan saran untuk mengembangkan hutan desa di wilayah Desa Siponjot, Kecamatan Humbang Hasundutan.

Transfer ipteks terkait dengan hutan desa dilanjutkan dengan sesi focus group discussion terkait dengan kepemilikan hutan desa. Meskipun masyarakat desa sepakat dan sepaham atas pentingnya pembentukan hutan desa, tim pengabdian mengalami kendala karena wilayah hutan di Desa Siponjot telah diklaim sebagai milik warga yang terbagi-bagi menjadi banyak wilayah di sepanjang wilayah desa. Pemindahan hak milik dari warga menjadi hak milik negara (sebagaimana konsep hutan desa) menjadi hal yang sulit untuk diaplikasikan, mengingat sebagian besar warga merasa kurang tepat untuk mengalihkan tanah miliknya menjadi milik negara, meskipun itu untuk kepentingan bersama.

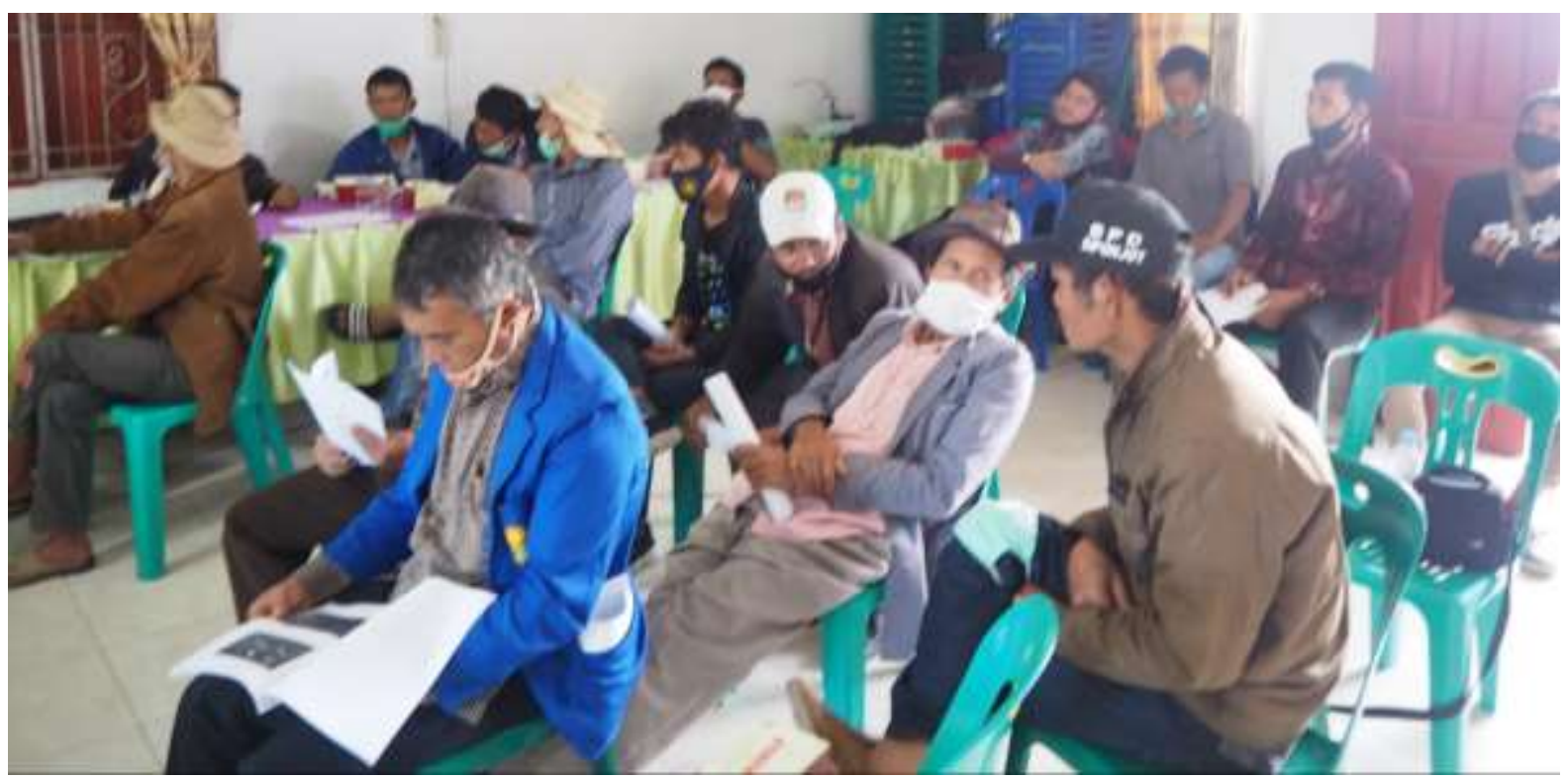

Gambar 3.3. Focus Group Discussion Pembentukan Hutan Desa

Pelaksanaan focus group discussion dilakukan oleh tim bersama dengan warga dan aparatur desa. Perlu kembali disampaikan bahwa seluruh rangkaian kegiatan di Desa Siponjot tetap memperhatikan protokol kesehatan dengan menjaga jarak antara warga peserta sosialisasi dan diskusi kelompok dengan tetap memakai masker. Seperti yang telah dikemukakan sebelumnya, pembentukan hutan desa memiliki pro dan kontra pada kondisi yang ada di masyarakat Desa Siponjot. Hutan desa memiliki status kepemilikan pemerintah dimana pengelolaannya dilakukan desa untuk kemakmuran masyarakat desa. Meskipun demikian, perpindahan status kepemilikan dari warga menjadi pemerintah menjadi isu yang belum dapat diselesaikan pada pelaksanaan pengabdian hingga laporan kemajuan ini ditulus. Meskipun pembentukan hutan desa tertunda, restorasi hutan di Desa Siponjot tetap terlaksana sebagaimana program direncanakan. 


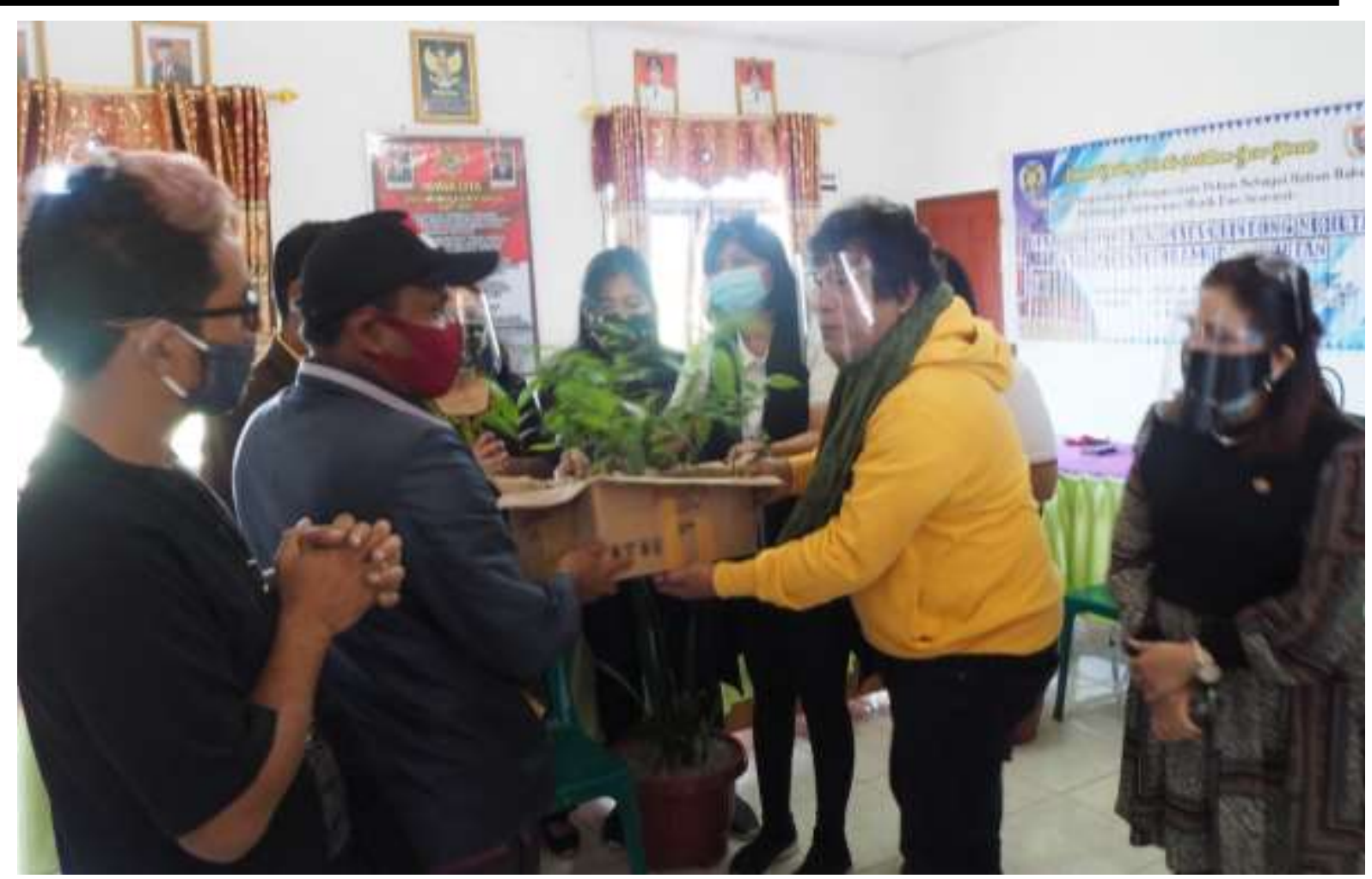

Gambar 3.4. Penyerahan Bibit untuk Restorasi Hutan Secara Simbolis

Tim pengabdian telah mempersiapkan seribu unit bibit tanaman hutan yang diberikan kepada masyarakat Desa Siponjot sebagai bagian dari program restorasi hutan di wilayah tersebut. Pemberian bibit (sebanyak enam varian tanaman) dilakukan selama dua tahapan, dimulai dari pemberian bibit secara simbolis kepada Kepala Desa Siponjot. Penyerahan sebanyak seribu unit bibit tanaman telah selesai dilakukan pada 17 Agustus 2020 dan telah diterima oleh warga. Pada kesempatan tersebut, hadir pula Camat Humbang Hasundutan sekaligus mengapresiasi kegiatan tim desa binaan di wilayah pimpinannya. Pemberian bibit secara simbolis juga dilakukan kepada Camat Humbang Hasundutan sebagai bukti pelaksanaan dan apresiasi dari aparatur setempat. 


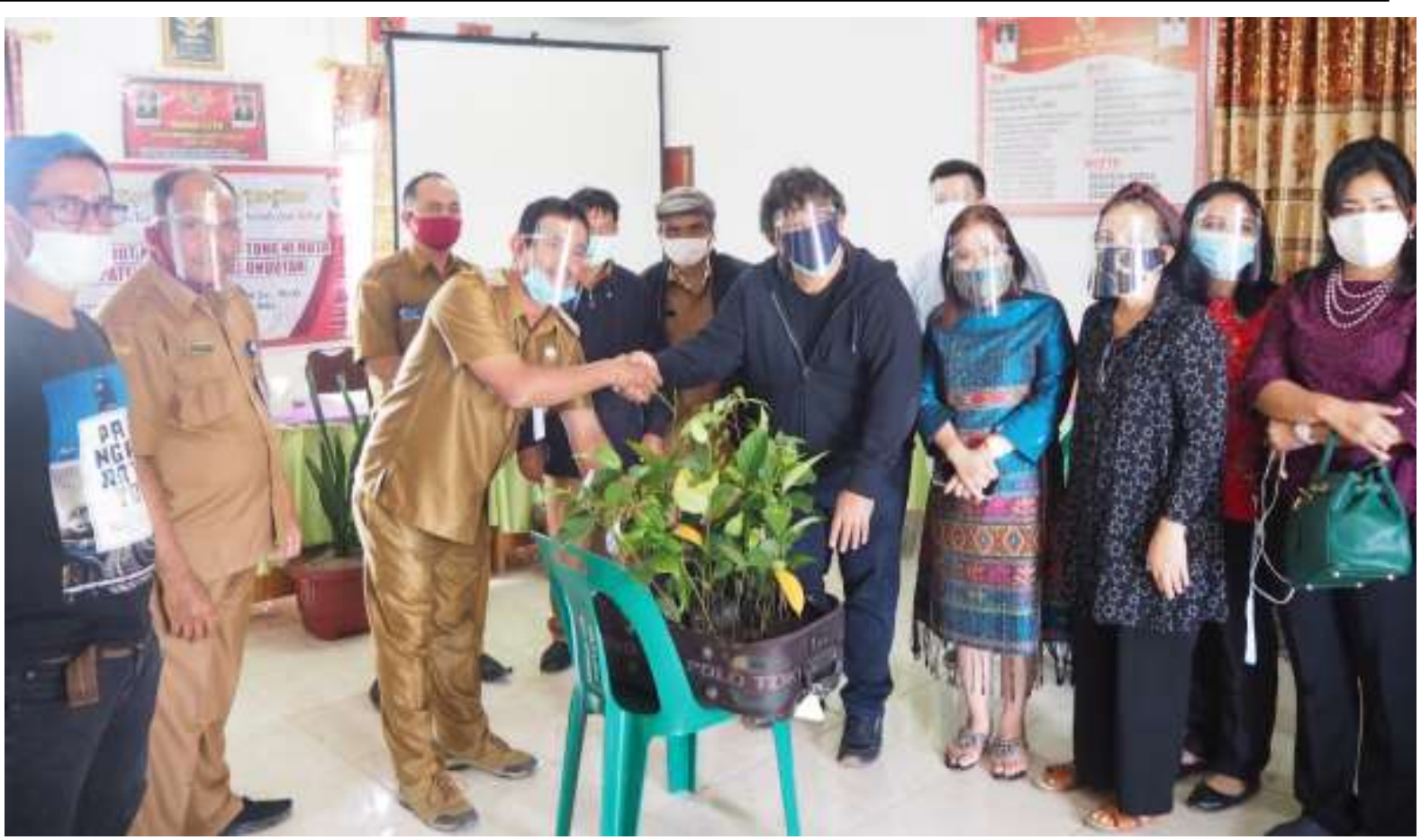

Gambar 3.5. Penyerahan Simbolis Bibit Restorasi kepada Camat Humbang Hasundutan

Tim pengabdian juga memberikan buku restorasi hutan dan pengelolaan hutan desa kepada aparatur desa. Pemberian buku tersebut dimaksudkan sebagai suplemen ipteks tambahan terkait pemahaman pentingnya restorasi hutan serta pembentukan hutan desa bagi kesejahteraan bersama masyarakat Desa Siponjot.
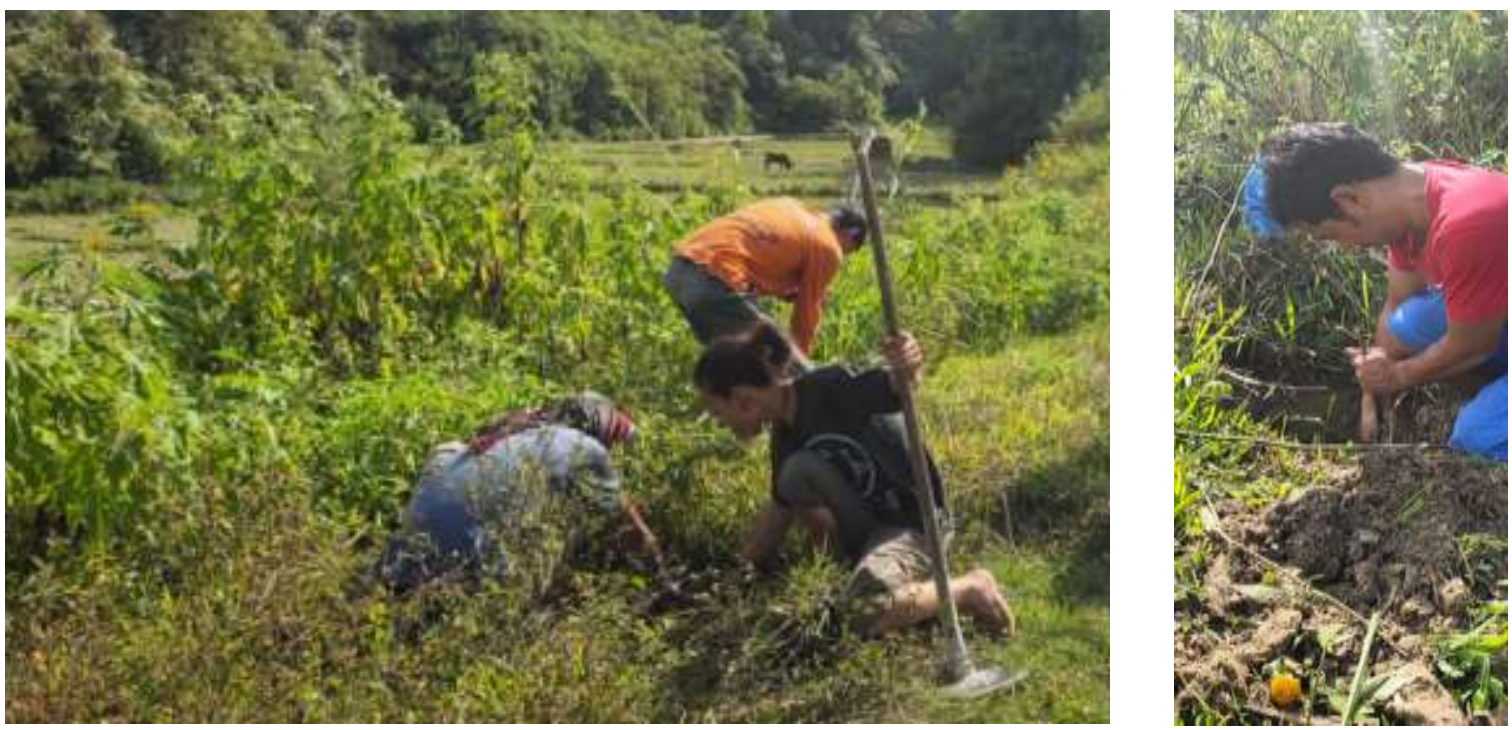

Gambar 3.6. Penanaman Bibit Restorasi Hutan

Masyarakat desa sangat antusias terhadap restorasi hutan yang selain menjadi potensi ekonomi bagi mereka, juga menjadi bahan baku produksi di masa yang akan datang. Pada kesempatan ini, warga secara proaktif menerapkan konsep marsirimpa dan bersama-sama menanam bibit untuk restorasi hutan di lahan milik warga. Secara bertahap, penamaman bibit seribu pohon mulai berjalan dengan baik. 

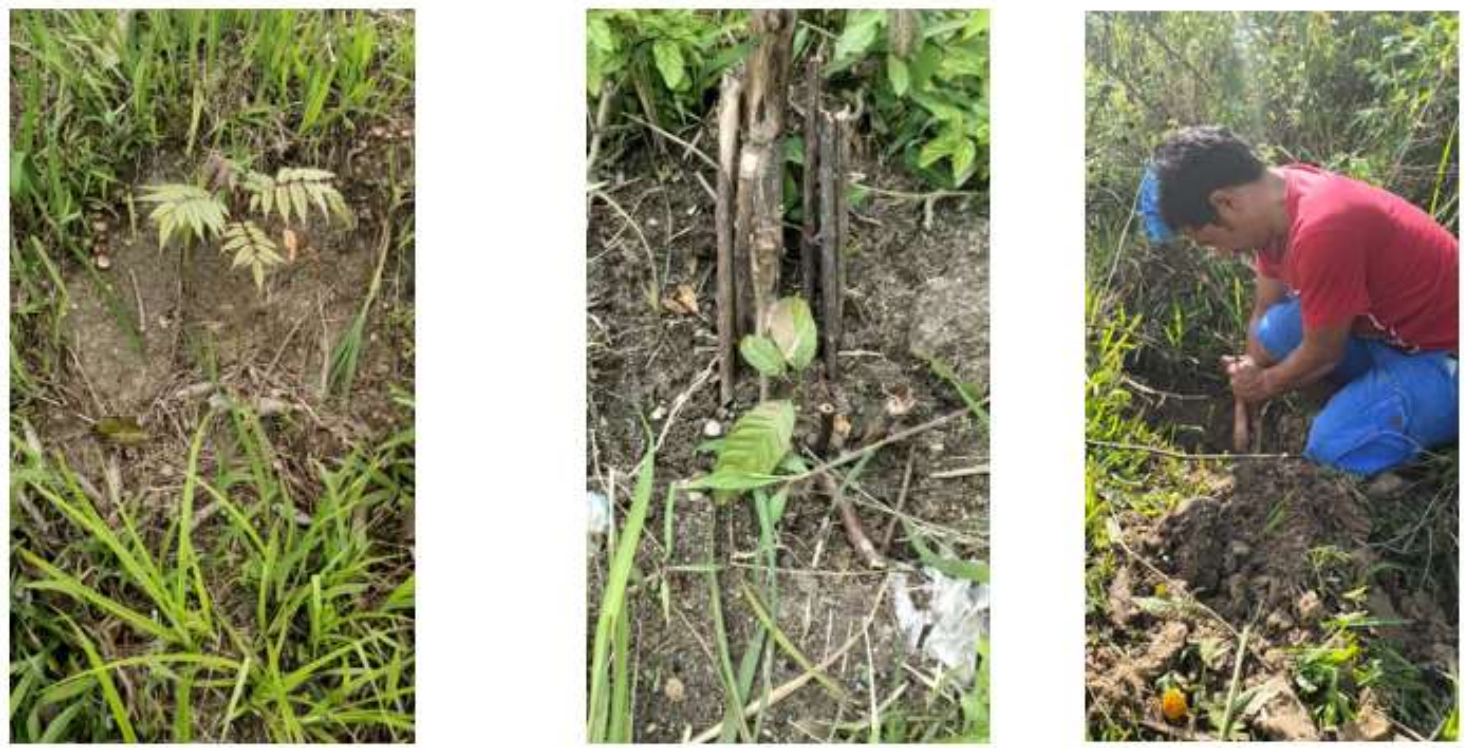

Gambar 3.7. Sampel Lokasi Penanaman Bibit Restorasi Hutan

Pemilihan lokasi penanaman bibit restorasi hutan desa sulit dilakukan karena pada dasarnya wilayah di Desa Siponjot merupakan tanah pribadi yang tidak bisa dijadikan hutan desa. Oleh karena itu, penanaman bibit ini dilakukan secara menyebar di seluruh wilayah desa, bukan di satu tempat untuk seluruh hutan desa tersebut.

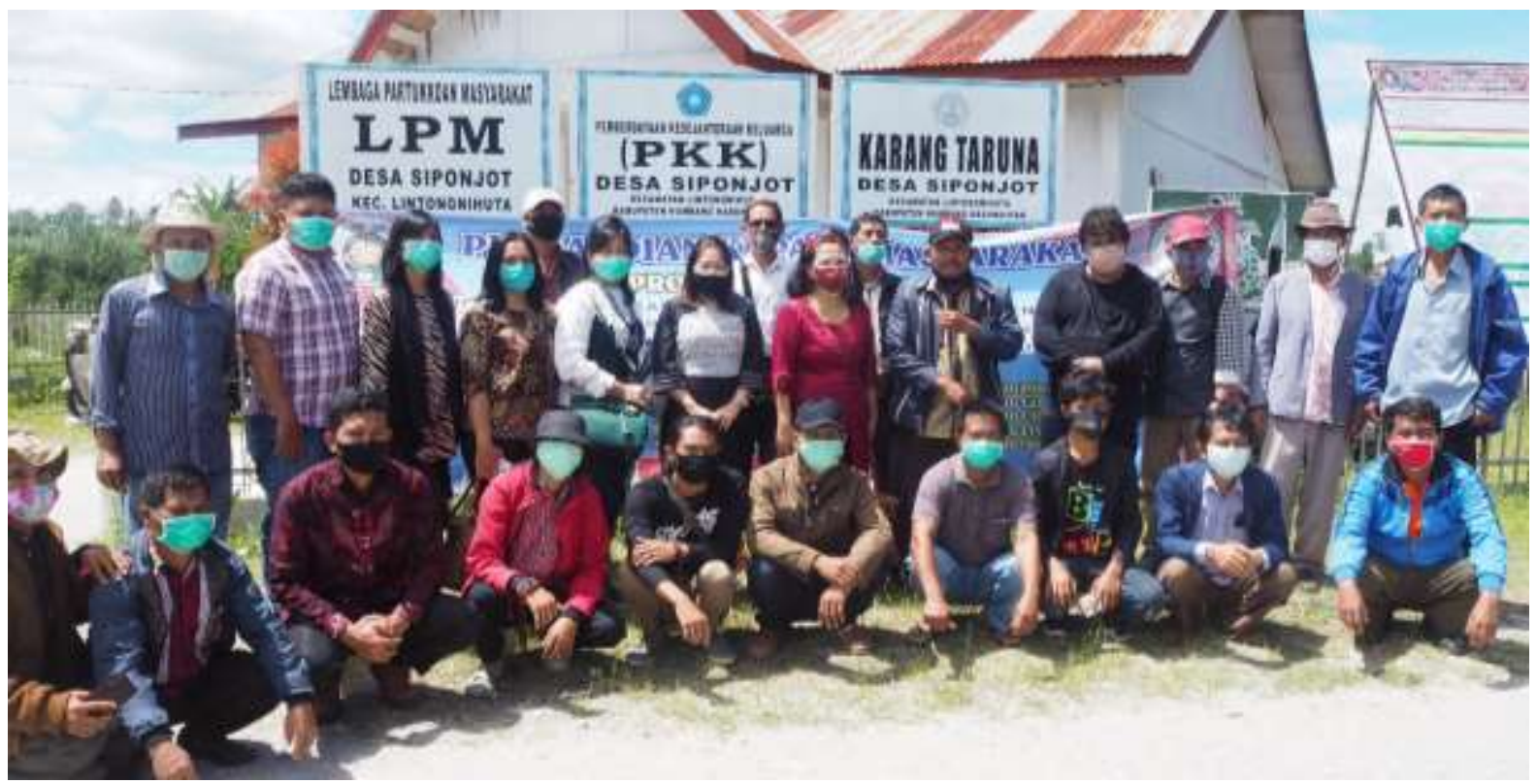

Gambar 3.8. Foto Bersama Masyarakat Desa

Pada tahapan pelaksanaan kegiatan pengabdian ini, tim pelaksana bersama para koordinator dan anggota pelaksana program desa binaan di Desa Siponjot ini mengucapkan kebahagiaan tersendiri atas antusiasme masyarakat dalam mengikuti program pengabdian serta dengan sukarela mau menerapkan ipteks yang diberikan kepada masyarakat. 


\section{KESIMPULAN}

Program restorasi hutan di Desa Siponjot terlaksana dengan baik dukungan dari masyarakat desa, dan aparatur desa. Warga secara proaktif menerapkan konsep marsirimpa dan bersama-sama menanam bibit untuk restorasi hutan desa. Secara bertahap, penamaman bibit seribu pohon berjalan dengan baik. Program pembentukan hutan desa mengalami kendala status kepemilikan desa. Meskipun demikian, status pelaksanaan restorasi hutan desa masih tetap dapat dilaksanakan dengan baik. Masyarakat dan pemerintah agar tetap menjaga dan merawat hutan desa agar dapat menghasilkan sumber bahan baku yang dapat mensejahterakan kehidupan masyarakat Desa Siponjot.

\section{UCAPAN TERIMAKASIH}

Terima kasih kepada Universitas Sumatera Utara khususnya Lembaga Pengabdian Masyarakat USU yang telah mendanai kegiatan pengabdian ini di bawah program Desa Binaan USU Tahun 2020. Terima kasih pula kepada seluruh warga Desa Siponjot serta dukungan aparatur pemerintah dalam mendukung pelaksanaan program ini.

\section{DAFTAR PUSTAKA}

Bambang Supriyanto. (2018). Social Forestry Implementation in Indonesia. 13th MEGAFLORESTAIS Building Momentum for Forestry in the Bioeconomy and Sustainable Development Storforsen, .

Budiono, R., Nugroho, B., Hardjanto, \& Nurrochmat, D. R. (2018). The village forest as a counter teritorialization by village communities in Kampar Peninsula Riau. Jurnal Manajemen Hutan Tropika, 24(3), 115-125. https://doi.org/10.7226/jtfm.24.3.115

Fisher, M. R., Moeliono, M., Mulyana, A., Yuliani, E. L., Adriadi, A., Kamaluddin, ... Sahide, M. A. K. (2018). Assessing the New Social Forestry Project in Indonesia: Recognition, Livelihood and Conservation? International Forestry Review, 20(3), 346-361. https://doi.org/10.1505/146554818824063014

Maqbool, S., Rafiq, M., Imran, M., Quadeer, A., \& Abbas, T. (2014). Creating Competitive Advantage Through Supply Chain Management. International Journal of Research in Commerce, IT \& Management, 4(1041). Retrieved from http://ijrcm.org.in/

Moeliono, M., Thuy, P. T., Bong, I. W., Wong, G. Y., \& Brockhaus, M. (2017). Social forestry-why and for whom? A comparison of policies in vietnam and Indonesia. Forest and Society, 1(2), 78-97. https://doi.org/10.24259/fs.v1i2.2484

Purba, M., \& Lumbanraja, P. (2019). Empowerment of Silaban margu arts sanggar as crafts of Batak Toba music tradition instruments in Huta Sitangkuban village Siponjot Kecamatan Lintong Ni Huta district Humbang Hasundutan Department of Ethnomusicology, Cultural Sciences, Universitas Sumatr. ABDIMAS TALENTA: Jurnal Pengabdian Kepada Masyarakat, 4(2), 647-655.

Santika, T., Meijaard, E., Budiharta, S., Law, E. A., Kusworo, A., Hutabarat, J. A., ... Wilson, K. A. (2017). Community forest management in Indonesia: Avoided deforestation in the context of anthropogenic and climate complexities. Global Environmental Change, 46(August), 6071. https://doi.org/10.1016/j.gloenvcha.2017.08.002 